\title{
Desenvolvimentismo e institucionalização partidária: o trotskismo invulgar do POR \\ (1952-1960)
}

Mabelle Bandoli ${ }^{1}$

\section{Resumo}

O objetivo deste artigo é discutir as principais características organizativas e programáticas do Partido Operário Revolucionário (de sua fundação em 1952 a 1960), avaliando seu posicionamento diante dos projetos de desenvolvimento nacional em voga nos anos 1950 e a relação desse posicionamento com os arranjos institucionais do partido. 0 ideário desenvolvimentista adotado pelos governos da década de 1950 - principalmente no governo Juscelino Kubitschek contou com a adesão de boa parte da esquerda marxista da época, o que incluía, além do trotskista POR, agremiações como o Partido Comunista do Brasil (PCB) e a Liga Socialista Independente (LSI). As variações entre os programas desses partidos e suas formulações sobre o desenvolvimentismo, além das diferenças entre seus princípios organizativos foram tema de nossa pesquisa de mestrado, que tem parte dos resultados da investigação feita sobre o POR apresentados neste texto. Buscamos, portanto, compreender os diferentes níveis dessa adesão programática entre os partidos da extrema esquerda (ou a existência de formulações críticas ou alternativas), na tentativa de lançar luz sobre um aspecto, a nosso ver, marginalmente tratado das pesquisas sobre o tema, que é o dos programas partidários de orientação marxista que debatiam os pressupostos pecebistas - estes mais amplamente investigados pela produção científica. Para debater a maneira como se combinaram seus princípios institucionais e a elaboração do programa específico do POR orientamos nossa leitura pelas proposições teóricas de Panebianco e Duverger. Esta pesquisa foi realizada com base em fontes bibliográficas e documentais, especialmente o jornaldo POR - o "Frente Operária"- além de entrevistas com ex-militantes. Como resultados, observamos que os traços originários do POR foram determinantes para a conformação do seu programa político, pois obrigaram os trotskistas a lidar com a presença de duas instituições externas fortes: o Bureau Latinoamericano da IV Internacional e o PCB. Isso significou uma diminuição de sua autonomia organizativa e a consequente diminuição da democracia interna no partido - dois indicadores que constam entre

\footnotetext{
1 Doutoranda em Ciência Política pela Universidade Federal do Paraná. Professora de Ciência Política no Instituto Federal do Paraná - Campus Paranaguá. E-mail: mabelle.bandoli2@gmail.com.
} 
as propostas de Panebianco para medir níveis de institucionalização partidária.

Palavras-chave: Trotskismo no Brasil; Partidos de esquerda no Brasil; Institucionalização partidária; Desenvolvimentismo e Marxismo.

\section{Introdução.}

O Partido Operário Revolucionário (POR) é um caso singular na história dos partidos marxistas brasileiros. Suas peculiaridades se fazem notar até mesmo nas datas que delimitam seu período de vigência: costuma-se adotar o dia 15 de novembro de 1952 (lançamento do jornal Frente Operária) como marco inicial das atividades do núcleo pioneiro de militantes, embora o primeiro congresso tenha se realizado apenas em fevereiro de 1964; já sua extinção é freqüentemente datada do ano de 1990 (quando o jornal e órgão central do partido deixa de circular). Em todo caso, o período de sua existência é inegavelmente longo - o que é incomum e mesmo improvável para partidos com as características do POR: clandestino, situado sempre na extrema esquerda do espectro político brasileiro, de diminuto efetivo de militantes.

As rupturas que fez com uma boa parte dos partidos de esquerda - tanto com seus antecessores quanto com aqueles com os quais concorria - somaram-se à delicada condição de uma acentuada fragilidade organizativa que precisava sobreviver a dois gigantes implacáveis: a relação de dominação imposta por sua instituição patrocinadora, o Bureau Latino Americano da IV Internacional e a hegemonia do Partido Comunista do Brasil no ambiente. Ao reunir todas essas características, o POR encarna, sem sombra de dúvidas, um objeto desafiador para qualquer análise.

Esta pesquisa foi realizada pela análise de fontes bibliográficas e documentais (o jornal "Frente Operária", veículo central do partido até 1990). A inexistência deestatutos e programas "oficiais" - ou seja, dedocumentos partidários sistematizados em um corpo textual elaborado e aprovado pelas instâncias partidárias, tal como se encontravam em outros partidos clandestinos da época, como no Partido Comunista Brasileiro (PCB) ${ }^{2}$ e a Liga Socialista Independente

\footnotetext{
2 Todos os estatutos e programas do Partido, desde sua fundação em 1922, estão disponíveis em:

http://www.fmauriciograbois.org.br/portal/cdm/revista.int.php?id_sessao=33\&id_ publicacao $=28 \&$ id_indice $=2037$
} 
(LSI) 3 caracterizou as atividades do POR até o ano de 1964, quando seus militantes se reúnem para o I Congresso do Partido. A obtenção das informações aqui trabalhadas foi resultado da montagem de um "quebra cabeças": os dados foram pinçados, em boa parte, dos textos veiculados no "Frente Operária" 4. 0 jornal tinha grande importância para a organização, pois contribuía para a manutenção da sua identidade e refletia a distribuição das tarefas e do poder entre os seus membros. As lacunas de dados decorridas da natureza dessas fontes foram diminuídas com informações obtidas em entrevistas gentilmente concedidas por ex-membros do Partido, os professores Ruy Fausto e Tullo Vigevani.

Objetivamos com este artigo apresentar alguns dos principais resultados obtidos em nossa pesquisa de mestrado ${ }^{5}$, que nos possibilitaram discutir as principais características organizativas do POR e as conseqüências dos seus arranjos institucionais para a formulação de seu programa- que buscava ser, como declarado desde os primeiros passos do Partido, uma alternativa à esquerda do PCB em um contexto político que impunha aos partidos da extrema esquerda que se posicionassem diante dos projetos governamentais e intelectuais de desenvolvimento nacional baseado na ampla industrialização do país e na alteração no seu status de produtor de artigos primários no mercado internacional. 0 ideário desenvolvimentista adotado pelos governos da década de 1950 principalmente no governo Juscelino Kubitschek - contou com a adesão de boa parte da esquerda marxista da época, o que incluía, além do trotskista POR, agremiações como o Partido Comunista do Brasil (PCB) e a Liga Socialista Independente (LSI). A industrialização se tornou a meta comum entre governos e boa parte da esquerda, e essa comunhão chegou a possibilitar acordos e alianças políticas entre partidos ligados à burguesia industrial urbana e grupos de ideologia anticapitalista. As variações entre os programas dessas organizações e suas formulações sobre o desenvolvimentismo, além das diferenças entre seus princípios

3 O documento oficial da LSI, intitulado "Projeto de Programa e Estatutos da Liga Socialista Independente", aprovado por unanimidade em um fórum coletivo dos militantes da LSI, em 1956, encontra-se disponível no Acervo do Arquivo Edgard Leuenroth, na Unicamp.

4 Foram analisados os números: 2 de dezembro de 1952; 4, 5, 6, 7, 8 e 9 de abril, junho, julho, agosto, setembro e outubro de 1953; 14, 15, 16 e 17 de fevereiro, maio, agosto e setembro de 1955; o número 18 de maio de 1956; uma edição sem número de outubro de 1957 e as edições no 31, 32 e 33 de setembro, outubro e dezembro de 1959.

${ }^{5}$ A dissertação de conclusão de curso de Mestrado em Ciência Política "A ExtremaEsquerda no Brasil: As Organizações Partidárias Marxistas e Suas Definições Programáticas nos Anos 1950" foi defendida e aprovada no dia 14/05/13, no Departamento de Sociologia e Ciência Política da Universidade Federal do Paraná. 
organizativos foram tema daquela pesquisa, que tem parte dos resultados da investigação feita sobre o POR apresentados neste texto.

Os traços originários e a evolução das escolhas do partido trotskista no âmbito da organização de sua militância foram determinantes para a conformação de seu programa, pois obrigaram a agremiaçãoa lidar com o desafio colocado pela presença de duas fortes instituições externas: o Bureau Latino-Americano da IV Internacional e do próprio PCB. Essa proximidade significou, concretamente, uma diminuição progressiva de sua autonomia organizativa e a conseqüente diminuição da democracia interna no partido, que passou a transferir, progressivamente, todo seu processo decisório para as mãos dos altos dirigentes das suas organizações patrocinadoras externas.

É imprescindível, para os efeitos almejados por este artigo, que definamos que por democracia interna entendemos a forma de distribuição e exercício do poder decisório interno. Levamos em consideração, para a investigação dessa variável, a existência de mecanismos estáveis em toda a estrutura partidária que permitissem a participação constante e ativa dos militantes em diferentes níveis, na definição dos rumos políticos e ideológicos da organização. Assim, tão importantes como os procedimentos para a escolha de lideranças partidárias (já que a seleção de candidatos a cargos eletivos, se não inexistente, era muito fortuita na vida de partidos clandestinos como o POR), mas também a possibilidade de participar dos círculos mais altos da decisão da agenda política, bem como de organizarinternamente grupos de oposição e concorrência a tais espaços, mantendo-se um nível mínimo da estabilidade partidária.

\section{I- A fundação do Partido Operário Revolucionário (POR): o surgimento de um "trotskismo sui generis" no Brasil.}

Fundando a chamada "terceira geração de trotskistas no Brasil" (KAREPOVS; NETO, 2007)o partido reunia, em 1952, ex-membros do PSB (Partido Socialista Brasileiro) e do extinto PSR (Partido Socialista Revolucionário), também de orientação trotskista. As motivações para sua criação são ligadas às necessidades de organizar nacionalmente os militantes identificados com a IV Internacional6, num processo deflagrado pela sua dinâmica de cisões internas - principalmente a que vinha se desenvolvendo entre os dirigentes argentinos J. Posadas e

6 A Quarta Internacional é uma organização comunista internacional fundada na França em 1938, por Trotsky e seus seguidores. O objetivo era criar uma organização de oposição ao movimento centralizado em Stálin, mas mantendo o vínculo com a tradição bolchevique. 
Nahuel Moreno (COGGIOLA, 1984). Havia naquele momento uma necessidade da nova coalizão dirigente da IV Internacional de buscar organizações trotskistas menos elitistas e mais próximas às camadas populares (KAREPOVS; NETO, 2007). A mudança de estratégia correspondia a uma transformação no jogo de forças políticas da organização que seria fundamental para a fundação do POR.

A disputa entre os dirigentes argentinos se deveu à orientação política decidida no III Congresso da IV Internacional, que ocorreu em 1951 na cidade de Paris. Nesse congresso, o então secretário-geral, o grego M. Raptis (em codinome Michel Pablo) apresentou um polêmico conjunto de teses que, ao serem aprovadas, reorientaram toda a política dos partidos filiados. Nesses textos, encontravam-se as bases de uma vertente do trotskismo que ficou conhecida como "pablismo" (COGGIOLA, 1984).

Em essência, os textos defendiam que o mundo vivia um período diferente daquele no qual a IV foi fundada: o conflito entre o imperialismo americano e os Estados operários encabeçados pela URSS estava em ponto de ebulição e uma nova guerra mundial viria a irromper em curto prazo. Convertida em guerra civil internacional, o conflito colocaria as massas em combate primordial ao imperialismo, o que seria apenas o primeiro momento de um longo processo que se estenderia para uma luta contra a burocracia stalinista (idem).

A emergência da guerra abreviaria o "tempo histórico" disponível para a construção de partidos "verdadeiramente revolucionários" (trotskistas). As massas estariam animadas pelos importantes processos de transformação social em curso no leste europeu e na China, e eles vinham acontecendo sob a direção soviética. Todos esses fatores empurravam o comando da provável revolução para as mãos da burocracia stalinista: somente "séculos de transição" para o socialismo poderiam diluir tamanha força política (ibidem).

Depois de vencer a guerra contra o imperialismo, se abriria o momento de levar as massas a lutar diretamente contra o stalinismo. Somente então os trotskistas se empenhariam em puxar a política soviética para a esquerda, fazendo surgir tendências centristas que acabariam por prevalecer sobre o "oportunismo direitista" vigente. Para cumprir cada uma das etapas dessa jornada, os trotskistas tinham a tarefa urgente de se integrar no real movimento das massas. 0 primeiro passo a ser dado era integrar os militantes trotskistas nos partidos comunistas em todo o mundo, com o objetivo de influenciar sua política. Assim, a partir de dentro, se iniciaria o longo processo de reconquista do imenso aparato controlado por Stálin. 
A política que ficou conhecida como "entrismo sui generis" foi aprovada e provocou a primeira divisão da IV Internacional: em novembro de 1953, as seções partidárias que optaram por se opor às teses pablistas organizaram o Comitê Internacional da IV Internacional (CI). A fração que se manteve ligada à direção de Pablo reuniu boa parte dos partidos trotskistas (as seções francesa, inglesa, suíça e americana) foi chamada de Secretariado Internacional (SI).

Na América Latina, o Congresso devia ainda decidir sobre a disputa entre as organizações lideradas por Nahuel Moreno e J. Posadas para representar oficialmente a IV Internacional na Argentina e organizar o trabalho nos países vizinhos. Na época, Posadas defendia que as atenções fossem voltadas ao diálogo com os movimentos nacionalistas, o que o tornava mais compatível com a política recém aprovada. Seu grupo foi declarado seção argentina da IV, e ele se manteve como o encarregado da organização do Bureau LatinoAmericano da Internacional, o BLA. Seguindo na oposição à direção pablista, Moreno apoiou o CI, e, em 1954, reuniu-se a dirigentes de outros partidos do continente para formar o Secretariado LatinoAmericano do Trotskismo Ortodoxo (SLATO), uma organização concorrente ao BLA (COGGIOLA, 1984).

No Brasil, o incipiente POR aderiu ao SI. Desde o início, suas atividades estavam intimamente ligadas ao trabalho de Posadas no continente, já que sua criação foi fruto de uma decisão do Bureau e, portanto, a linha defendida por ele era, no mínimo, a mais provável a ser seguida pelo partido.

Foi ainda em meados de 1952 que Guillermo Almeyra chegou a São Paulo, vindo da Argentina, na condição de delegado do BLA, com a tarefa de estabelecer ligação com os trotskistas brasileiros, editar um jornal e liderar um grupo. Em novembro do mesmo ano foi lançada a primeira edição do "Frente Operária", em torno do qual se nucleou a equipe de militantes que constituiu o POR (PEREIRA NETO, 2005).

Essa marca de nascença conferiu ao POR uma especificidade em relação aos demais partidos de origem trotskista na América Latina: em sua maioria, eles surgiam motivados essencialmente pelas cisões já existentes nos partidos comunistas, o que lhes conferia maior identidade e independência frente à Oposição de Esquerda (KAREPOVS; NETO, 2007). Ao longo dos anos 1930, as direções de muitos partidos comunistas enfrentaram o surgimento de tendências internas que passaram a disputar o poder partidário de maneira cada vez mais acirrada; muitas vezes, os conflitos eram resolvidos pela expulsão de grupos inteiros das fileiras comunistas e estes respondiam às sanções formando novos partidos. Boa parte dessas dissidências 
aderiu à organização da Oposição de Esquerda, criando os partidos que compuseram as primeiras seções da IV Internacional. Portanto, as primeiras organizações trotskistas se fundaram sobre bases que já vinham sendo construídas nos processos de disputa de frações que ocorriam dentro dos PC's, o que conferia a cada uma delas certo nível de identidade e de organicidade entre seus membros.

No Brasil, o padrão de surgimento de novos grupos, em geral, foi o mesmo. Os primeiros partidos trotskistas surgiram de dissensões que começaram a se manifestar nas fileiras do PCB em 1927 (FERREIRA, 2005). Os contatos iniciais entre as frações do Partido Comunista e os trotskistas foram liderados por Mário Pedrosa - que em 1938 viria a ser o único latino americano presente no Congresso de fundação da IV. 0 diálogo gerou o Grupo Comunista Lênin, surgido em 1930 da união de militantes que vinham se opondo internamente ao PCB e resolveram se filiar à Oposição de Esquerda Internacional. 0 grupo não sobreviveu ao afastamento de Pedrosa e logo se desfez. Muitos de seus membros se desmobilizaram, mas outros aproveitaram sua herança teórica e se reuniram com outros dissidentes comunistas, fundando a Liga Comunista do Brasil (LC).

A história de cisões e reagrupamentos se repete, e ao longo dos primeiros vinte anos do trotskismo no Brasil são criadas outras três organizações: A Liga Comunista Internacionalista (LCI), o Partido Operário Leninista (POL) e o Partido Socialista Revolucionário (PSR) (FERREIRA, 2005). Ainda que tenham sucumbido a dificuldades que se somaram à sua imaturidade e a fragilidade organizativa, cada um desses grupos conseguiu formar um legado que foi retomado em maior ou menor medida pelos seus sucessores. Além disso, o fato de comungarem a oposição ao PCB e a filiação à IV Internacional garantia que eles mantivessem traços de identidade que se conservaram ao longo do período.

Nesse sentido, a fundação do POR significou uma verdadeira ruptura geracional na história do trotskismo brasileiro. Dainis Karepovs e José Castilho Marques Neto (2007) afirmam que sua criação não segue nenhum fio de continuidade em relação às demais organizações. Em suas palavras:

A maneira como foi impulsionada e as características do período denotam que a organização não tinha como fazer uso das experiências anteriores, e suas ações denotam que o grupo iniciava suas ações praticamente do zero. Uma evidência disso é que as caracterizações feitas pela IC e pelo PCB são retomadas pelo POR, que defende a tese de que o Brasil deveria ser classificado como um "país agrário e com restos feudais ou semifeudais". Tais noções, ainda em voga no PCB haviam sido 
criticadas e abandonadas pelos oposicionistas de esquerda desde 1930. (KAREPOVS \&NETO, 2007, p. 148).

$\mathrm{O}$ acúmulo político de vinte anos de atividades dos trotskistas no Brasil, de fato, não foi totalmente aproveitado pelo partido. Mas o abandono das críticas elaboradas por essa tradição não deve, a nosso ver, ser creditada a um total distanciamento do POR em relação às outras organizações. Alguns de seus militantes vinham dos partidos acima citados; além disso, o "Frente Operária" (jornal e órgão central do partido) chegou a publicar artigos de Hermínio Sachetta (com o codinome Carlos Matos) - que veio a ser, anos mais tarde, a grande liderança da Liga Socialista Independente ${ }^{7}$ e ex-membro do PCB (Partido Comunista Brasileiro) e do PSR (Partido Socialista Revolucionário) - nos quais se debatiam temas como a concepção leninista de partido ${ }^{8}$. A questão é que essa transição entre o PSR e o POR acontecia durante a intervenção da IV Internacional - Bureau Latino Americano no Brasil, mas ainda antes da consolidação da relação entre as duas organizações e das políticas mais importantes que surgiriam dessecontato, como a do entrismo, como veremos a seguir (PEREIRA NETO, 2004).

Há, portanto, outros fatores que devem ser questionados quando discutimos os significados das rupturas programáticas do POR com a tradição que as organizações trotskistas vinham desenvolvendo no Brasil. Entre eles, está aquele que, segundo Murilo Leal Pereira Neto (2004), talvez seja seu principal traço originário: o POR nasce e se desenvolve como um partido de legitimação externa (PANEBIANCO, 2005). Na política desenvolvida pelo partido em todo o período que aqui discutimos, "se verifica a presença de uma instituição externa, o Bureau Latino-Americano (BLA) da $4^{\text {a }}$ Internacional, patrocinando o nascimento do partido e servindo como fonte de legitimação de sua liderança" (CHAGAS, 2010). A proximidade com o BLA e a natureza dessa relação influenciou sobremaneira toda a constituição das políticas, dos programas e da própria organização do partido.

\section{II- O POR como organização: legitimação externa, democracia interna e autonomia organizativa.}

A relação com uma instituição externa patrocinadora (PANEBIANCO, 2005) impunha uma série de desafios extras à

\footnotetext{
${ }^{7}$ A LSI fundou-se em 1959, reunindo militantes trotskistas e luxemburguistas que romperam com a IV Internacional. Ver FERREIRA, 2005 ; OLIVEIRA, 2007; PEREIRA NETO, 2005.

${ }^{8}$ A informação sobre o codinome de Sachetta está disponível em PEREIRA NETO, 2004. O artigo escrito por Sachetta tem o título: "A Organização Leninista do Partido" e foi publicado no "Frente Operária, no 5, de maio de 1952.
} 
organização do partido. Além das rupturas com o acúmulo teórico do trotskismo brasileiro, o POR nasceu sob significativa falta de autonomia, o que o enfraquecia política e - ao que tudo indica programaticamente.

A forte dependência em relação ao BLA não parece ter sido recompensada à altura dos prejuízos: não trouxe novas possibilidades de estabelecer trocas vantajosas com os organismos internacionais que o compunham e nem permitiu ao partido que aproveitasse as informações privilegiadas do cenário mundial - o que poderia ser de grande valor à formulação de sua política. A avaliação dessa relação é bem sintetizada no depoimento de Ruy Fausto9.

0 peso do Bureau Latino-Americano era muito grande. Havia às vezes fricções entre o grupo nacional e o BLA. Mas principalmente quando Posadas passou a dominar o Bureau, tenho a impressão de que a opinião dele se impunha, em última instância.

Segundo KAREPOVS \& NETO (2007), o BLA exercia forte fiscalização dos debates ocorridos internacionalmente, o que alimentava e agravava as conseqüências da política de centralismo extremo. A exacerbação do "culto da personalidade" de J Posadas entre os partidos do BLA se somou a uma política de características monolíticas. A indicação de Posadas era que as relações da organização internacional com os partidos seguissem a fórmula: "centralismo $90 \%$, democracia 10\%" (KAREPOVS; NETO, 2007). Não raro, o Bureau ordenava que se enviassem delegados às suas seções, o que mantinha as organizações trotskistas latino-americanas sob rédeas curtas. No cotidiano do POR, não era diferente. Segundo Tullo Vigevani, que passou a militar oficialmente na organização a partir de dezembro de 1960,

a autonomia do POR era mínima. O Bureau Latino Americano estabelecia diretrizes gerais, análises sobre política internacional e nacional. Os grupos nacionais tinham autonomia, como se dizia na época, para "aplicar", interpretar e executar as diretrizes vindas do Bureau. E, antes da crise da IV Internacional de 1960, as diretrizes do Secretariado Internacional que ficava em Paris. ${ }^{10}$

O controle excessivo trouxe inúmeros problemas para a manutenção desses partidos. Entre os mais evidentes, estão aqueles que se referem à preservação da sua identidade organizativa. A seção brasileira apresentava um dos casos mais graves. A asfixia imposta pelo BLA ao livre desenvolvimento do POR chegou a colocar em risco a sua viabilidade.

\footnotetext{
9 Entrevista realizada em 18 de abril de 2013.

10 Entrevista concedida em 19 de abril de 2013.
} 
No caso brasileiro, não houve sequer manifestações organizativas que refletissem o quadro internacional do trotskismo, como na Argentina, por exemplo. Havia tanta rigidez que, antes de 1966 não houve qualquer manifestação pública de dissidência ou discordância e os militantes descontentes simplesmente abandonavam o POR (KAREPOVS; NETO, 2007, pág. 158).

Dessa forma, os dois traços originários do POR acima ressaltados estão profundamente relacionados, desembocando na composição de uma organização partidária que apresenta como feições mais significativas: i) uma baixíssima autonomia organizativa, situação que só se agravou no período pós-entrismo, como veremos; ii) e uma centralização acentuada, combinada a uma diminuição progressiva dos níveis de democracia interna. Para melhor vislumbrar as articulações entre essas características, passemos à análise da estrutura do POR.

Em 07 de agosto de 1953, os trotskistas expõem alguns de seus princípios organizativos fundamentais. Depois de afirmar, dois meses antes (POR, 1953), a necessidade de construir um "instrumento" para uma luta que pudesse resolver "as tarefas democrático-burguesas, liquidando os latifúndios e expulsando o imperialismo", os trotskistas seguem explicitando suas orientações programáticas nas páginas de seu jornal, dessa vez contrapondo-as àquelas reivindicadas pelo PCB. A disputa em torno das noções de "internacionalismo", "marxismoleninismo" e "centralismo democrático", mais que uma mera contenda em torno de termos, nos parece significativa para a definição daquilo que o POR buscava ser - o que expunha, na maioria das vezes, em contraposição àquilo que buscava não ser.

O partido deve ser internacional e internacionalista, deve ser baseado na ciência, no marxismo- leninismo deve ser proletário na sua composição social, deve ser flexível na sua tática, mas inflexível na sua estratégia orientada para a Revolução Mundial e o socialismo. Sua organização deve estar de acordo com suas concepções. 0 stalinismo é a negação dessas condições: internacional por subordinação ao Kremlin, não é internacionalista. [...] O nacionalismo chauvinista do stalinismo russo se reflete no nacionalismo chauvinista dos partidos comunistas em seu conjunto [...]. A burocracia é pequenoburguesa social e ideologicamente. [...] Sua "ideologia" reflete essa situação social. Por isso liquida o marxismo-leninismo. [...] E, naturalmente, a organização do stalinismo está de acordo com o caráter da burocracia. 0 centralismo democrático do leninismo, em que a política democrática é fruto da elaboração comum, com o controle da base sobre os dirigentes, com a discussão interna e a unanimidade externa para a aplicação da linha resolvida democraticamente pela maioria é substituído pelo centralismo 
burocrático, pela ditadura do Kremlin sobre as direções nacionais dos PC's e das direções sobre a base, pela políticado monolitismo e pela supressão da democracia interna. (POR e SOUZA. Frente Operária, 5 de junho 1953, noㅗ, s/p.)

Observe-se que há, nesse texto, uma correlação clara entre orientações ideológicas, programa partidário, autonomia organizativa frente às instituições patrocinadoras e democracia interna. Os trotskistas mobilizavam, na sua crítica à política comunista, boa parte daquelas questões que se mostrariam mais difíceis de equacionar em sua própria trajetória. A primeira delas é a da falta de autonomia em relação ao BLA. Além dos contornos já enumerados, esse traço conferiu ao POR uma maior debilidade nos mecanismos e espaços de democracia interna. Um bom panorama dessa fragilidade institucional, acrescida de um rigoroso centralismo, é exposto por Tullo Vigevani11:

[os estatutos] não existem, que eu saiba. Isso resulta de vários motivos. Um, e principal na minha avaliação, é a situação de clandestinidade e ilegalidade. As organizações marxistas e que se declaravam revolucionárias não tinham legalidade. Ainda que não fossem reprimidas no período pré 1964. Isso tornava a organização elástica/fluída, sem rigidez organizativa. Acrescentese ser o POR uma organização extremamente centralizada, particularmente por Posadas, que estava na Argentina. Os delegados do Burô Latino Americano que vieram organizar o trotskismo no Brasil nos anos 50 e 60 eram enviados por Posadas. O congresso de 1964 tinha a particularidade de chamar-se congresso. Mas papel semelhante tinham reuniões ampliadas, do comitê central ampliado, plenárias, etc.[...] a organização era centralizada. E havia hierarquia aceita. Iniciava-se com Posadas. Em seguida vinham seus delegados. Almeyra e, a partir de 1959, Gabriel Labat (conhecido como Diego). Eles dirigiam. Buscava-se o consenso para designar os dirigentes. Ao menos desde quando eu militei formalmente, dezembro 1960, nunca houve qualquer disputa para os cargos.

Segundo Murilo Leal Pereira Neto (2004), o número de militantes nesse período inicial girava em torno de 20 a 50 pessoas. Suas atividades se sediavam em São Paulo, Rio de Janeiro e Paraná, com expansão para outros estados nos anos 1960. A composição da direção inicial era a seguinte: Guillermo Almeyra, Secretário Político; Leôncio Martins Rodrigues, Secretário de Organização; Milton Camargo, Secretário de Finanças e Antônio Pinto de Freitas e depois Sebastião Simões de Lima, Secretários de Agitação.

Já os critérios e mecanismos para a escolha desses dirigentes, o estabelecimento das regras para a o desempenho de suas funções e

\footnotetext{
11 Entrevista concedida em 19 de abril de 2013.
} 
suas relações com as bases (tais como alternância de ocupantes nos cargos, prestação de contas, normas de centralização das decisões) não se encontram definidos, segundo os entrevistados, em nenhum documento oficial. Ao que tudo indica, a ocupação dos cargos era determinada de maneira informal, de acordo com as indicações dos delegados do BLA. Nas palavras de Ruy Fausto:

Não sei de nenhum documento definindo regras de funcionamento. Me espanta a precisão das suas informações. "secretário político", "secretário de organização" etc. Eu não sabia exatamente que estas eram as funções de uns e outros. Na prática, era de fato mais ou menos assim. As nomeações se faziam de cima para baixo. Por cooptação.

O tão criticado "centralismo burocrático" do PCB não foi, portanto, superado pelo POR. Sem a manutenção dos mecanismos básicos de participação e deliberação das bases, o modelo original de "centralismo democrático" criado pelos partidos comunistas e reivindicado pelos trotskistas não se realizou na prática da organização. Em seu lugar, encontramos uma forma de centralização mais próxima ao que Duverger chama de "centralismo autocrático". Nos seus termos:

[...] podem-se distinguir duas formas de centralização, uma autocrática a outra democrática, se considerar-se esse último termo como índice de uma vontade de manter o contato com a base. No centralismo autocrático, todas as decisões vêm do alto, e sua aplicaçãoé controlada localmentepor representantes da cúpula (DUVERGER, 1987, pág 92).

Ainda sobre essas diferenciações em torno da noção de centralismo democrático, acreditamos que vale sublinhar sua intensa ligação com as orientações ideológicas em disputa naquele momento. Em um breve resumo, Ruy Fausto as define:

Embora isso seja mais ou menos óbvio, como nomear as coisas é importante, eu diria: PCB - princípio organizatório: centralismo stalinista; POR - princípio organizatório: centralismo leninista; Liga[Socialista Revolucionária]: não sei; provavelmente mais democrática. Nos dois centralismos, as diretivas vinham de cima para baixo. Nos dois havia alguma discussão. Mas no quadro da variante leninista, a discussão era certamente mais viva, e havia lugar (sempre na cúpula, não na base), para verdadeiras divergências, o que só excepcionalmente ocorria na outra. [grifos do entrevistado]. 
Em 1955, o POR adere oficialmente à tática do entrismo. Seguindo as orientações de uma resolução política aprovada na III Conferência Latino-americana, realizada no Chile em março de 1954 e reafirmada pelo IV Congresso da IV Internacional, que foi realizado na França no final do mesmo ano, os trotskistas deviam priorizar seus esforços para "lançar-se a um trabalho de grande fôlego no seio da organização e do movimento de massas influído pelo PCB" (PEREIRA NETO, 2004).

Foi assim que, mais uma vez seguindo as determinações externas, o POR aderiu formalmente ao "entrismo". Em 1955, seus militantes começaram a ingressar no PCB para formar uma "ala revolucionária" e buscar maior audiência do que até então vinham obtendo, em especial entre as bases do partido stalinista. Esse entrismo acabou se mantendo, apesar das dificuldades, até 1963, quando o BLA convenceu-se de que o PCB era um partido irremediavelmente contrarevolucionário e decretou o final da experiência.

Antes disso, porém, a tática deixou suas marcas no desenvolvimento do partido. Segundo Pereira Neto (2004), esse foi um dos "momentos da história da organização que determinou mudanças drásticas da sua linha política, podendo-se mesmo falar em substituição de fins oficiais, tendo como conseqüência um abalo na identidade política do partido" (idem). De fato, o deslocamento dos escassos recursos da organização para a realização de uma tarefa tão extraordinária cobrou seu preço para a formulação programática dos trotskistas, como vermos adiante.

Além do programa, há uma dimensão que merece ser ressaltada, que é a do desgaste da militância do partido. Como vimos, as demais condições de ação oferecidas pelo POR (falta de autonomia e extrema centralização com a transferência do poder decisório da base para as direções externas), chegaram a colocar a sobrevivência da organização em risco, pois afastava cada vez mais seus membros da organização. Essa tensão foi ainda mais agravada pela hostilidade ambiental que encontraram no PCB (que chegou, em momentos anteriores de sua história, a proibir qualquer relação pessoal de seus membros com militantes de orientação trotskista) ${ }^{12}$. É nesse sentido que aponta o depoimento de Ruy Fausto:

0 entrismo era uma ilusão. A meu ver, ele não levou a nada. Ele rebentava os militantes, fornecia trabalho útil ao PC. E informações. Mas o que fazer com elas? Em geral, seria preciso não esquecer: $\mathrm{O}$ POR era um grupinho mínimo (ver os números no livro do Murilo). Seu forte era o fato de não ser stalinista. Quanto

\footnotetext{
12 Ver PEREIRA NETO, 2004.
} 
ao mais, estava mais ou menos fora do mundo. Pelo menos, fora do Brasil. Sabíamos muito pouco do que se passava, e tínhamos um esquema rígido que não poderia levar a nada.

Outra explicação para o fracasso do entrismo pode ser encontrada nas características da própria política e na natureza das organizações envolvidas. Muito próximo ao processo que Duverger chama de "nucleamento", o sucesso do entrismo pressupõe uma relação entre duas organizações na qual a "nucleadora" seja institucionalmente mais sólida que a nucleada - o que, obviamente, não era o caso do POR em relação ao PCB.

0 partido nucleador estabelece agrupamentos de ação comuns entre essas instituições e ele próprio nos escalões de base. Para eles, o nucleador exerce uma ação sobre o nucleado; podendo chegar a dominá-lo ou a desagregá-lo parcialmente. Evidentemente, o processo pressupõe que o nucleador possui um arcabouço muito mais forte que o do nucleado: é um pouco da aliançada panela de barro com a panela de ferro. 0 nucleamento é portanto utilizado sobretudo pelos partidos que se fundamentam na célula ou na milícia (DUVERGER, 1987, pág. 87).

Com uma organização tão frágil, os trotskistas não conseguiram concretizar os objetivos de sua tática. Essa é uma avaliação que aparece, inclusive, em boa parte dos textos que eles próprios produziram na época. Ainda que em nenhum deles se reconhecesse o fracasso do entrismo - e que somente tenhamos encontrado menções sutis à necessidade da construção de uma "política independente" nos escritos a partir do final de 1957 - o reconhecimento das inúmeras limitações da organização era uma constante, que se impunha como realidade inescapável a cada vez que o partido buscava apontar saídas para o movimento de massas ou explicar as razões para a não realização imediata de seus propósitos. A mutilação de sua capacidade de elaboração de proposições concretas e de alternativas programáticas é mais um dos efeitos da fragilidade institucional sentidos pelo partido.

\section{III- Programas, metas e objetivos do POR: entre a obediência ao BLA e a desconstrução do PCB.}

A construção autônoma das metas ideológicas do POR parece ter sido duplamente prejudicada por sua subserviência ao BLA e pelo entrismo no PCB. Por um lado, a organização não conseguia formular mais do que meras adaptações nacionais do modelo posadista. Murilo Leal Pereira Neto (2004) afirma que é possível encontrar os fundamentos básicos da linha política do POR brasileiro nas páginas do 
argentino "Voz Proletária". Lançado em junho de 1947, o jornal era nada menos que o porta-voz oficial do partido Grupo Cuarta Internacional, dirigido por J. Posadas. As leituras posadistas da política latino americana foram importadas pelo POR para o cenário brasileiro em inúmeras ocasiões.

Segundo o autor, o CGI trouxe novidades para a análise das Ciências Sociais da época - influenciado pela visão de mundo das elites sociais - quando valorizou, na leitura que fazia do peronismo, o papel ativo do operariado e das massas populares na formação do que se pode qualificar de "populismo" latino-americano, o que também valerá para o varguismo no Brasil. Outra característica das análises do grupo, impressa pelo seu secretário J. Posadas, foi o esforço de enraizamento no movimento operário - esforço que motivou a política do entrismo.

No primeiro número do "Frente Operária", em 1952, o POR afirma que o trabalhismo de Vargas é tratado como uma "expressão particular de um fenômeno mais abrangente, o nacionalismo latinoamericano" (PEREIRA NETO, 2004). No texto citado pelo autor ${ }^{13}$, as referências a Perón são constantes, mas seu governo aparece como de um nacionalismo "mais vulnerável que o de Perón devido a fatores de ordem econômica e social"; "o nacionalismo de Vargas era considerado tímido e marcado por constantes concessões ao imperialismo" (PEREIRA NETO, 2005).

Durante esse mesmo período, o PCB fazia uma avaliação bem menos branda da política getulista. 0 Partidão viva um período de desgaste em suas relações com o governo e trazia, em suas declarações, a expressão de "governo de traição nacional" para descrever o que acreditava ser o significado geral de suas políticas para os interesses gerais da nação. Dessa forma, a leitura que o POR apresentava sobre a figura de Getúlio, em 1952, não indica grandes aproximações com a do PCB. Tais aproximações se notam em outra questão, que acompanhará as avaliações dos trotskistas durante todo o período analisado: a noção de "atraso no campo" em oposição ao progresso urbano-industrial.

Em uma síntese das avaliações do POR sobre o governo Vargas, PEREIRA NETO (2004) apresenta algumas questões que nos parecem fundamentais para esta análise. Adiantando algumas proposições que se repetiram mais tarde, quando os trotskistas se debruçaram sobre a caracterização da burguesia nacional, Vargas era visto, antes de tudo, como um agente que se via pressionado entre duas das forças sociais mais conservadoras da época (os imperialistas e os latifundiários)

13 "O Nacionalismo na América Latina: comunistas ou fascistas?". O artigo foi publicado nonúmero 1 do "Frente Proletária", fonte da qual não dispomos diretamente. 
buscando, ocasionalmente, o apoio das massas para equilibrar essa relação. Frágil como a fração de classe que representava, toda vez em que se encontrava muito pressionado pelas massas ou pela esquerda, amparava-se no imperialismo, mostrando-se titubeante e pouco conseqüente do ponto de vista dos seus próprios interesses nacionalistas (PEREIRA NETO, 2004).

Em dezembro de 195214, o POR divulga um programa dedicado a expor as políticas getulistas contra as quais se opunha, bem como a convocar suas bases "à mobilização das massas". Nele, os inimigos a ser derrotados são o imperialismo, o Acordo Militar com os Estados Unidos e "sua política guerreira", a miséria e a fome, bem como a desorganização das massas trabalhadoras, especialmente no campo (PRADO JUNIOR, 2000).

Nesse mesmo texto, o partido apresenta algumas das características mais marcantes de sua orientação programática: caracteriza o Brasil como um país semi-colonial, mas depois fala na necessidade de "acabar com a exploração semi-feudal" bem como extinguir a exploração pelo sistema de meeiros. Essa combinação de conceitos remete, ao mesmo tempo, às reflexões de Caio Prado Jr. (o autor foi citado no no 7 publicado em agosto de 1953 do "Frente Operária", edição que apresenta a resenha de uma de suas obras mais importantes, o "Formação do Brasil Contemporâneo") e às noções mais etapistas do pensamento pecebista, justamente às quais Caio Prado Jr consagrou algumas de suas criticas mais fecundas. As oscilações entre os movimentos de aproximação e afastamento dos pressupostos comunistas se mostraram uma constante em todo o período analisado. Elas se verificam também nas primeiras determinações do partido acerca do programa democrático-burguês pecebista.

Ainda em 1953, o POR avaliava que o etapismo presente nas proposições pecebistas era uma questão programática e ideológica, referente ànecessidade da burocracia soviética de se manter no poder. 0 caráter essencialmente reformista de seu programa servia à manutenção dos líderes máximos do movimento comunista, que não teriam o menor interesse em questionar o status quo. Para os trotskistas, a noção de uma "revolução em duas etapas" seria essencialmente conservadora, porque "pretende conservar seus privilégios de casta burocrática - e, portanto, contra-revolucionário, pois vê na revolução o fim desses privilégios". (SOUZA in POR, 1953). Mas o mesmo raciocínio não foi aplicado às próprias formulações. Repetindo as noções gerais dos comunistas sobre o processo histórico,

\footnotetext{
${ }^{14}$ Frente Operária, n. 2, dezembro de 1952 “Contra o Imperialismo e seus agentes”.
} 
os trotskistas do POR viam no stalinismo um fenômeno transitório e identificavam no aumento da atividade industrial - e, portanto, na liquidação do "atraso" que significava o peso da atividade agrária na economia - o grande impulso para as transformações políticas. Na continuação do texto acima citado, encontramos as seguintes avaliações do cenário internacional:

A revolução colonial e fundamentalmente a magnífica revolução chinesa, abalou o capitalismo e mostrou que a URSS não é a única força dirigente do campo anti-imperialista. Ela deu também a perspectiva da revolução mundial, derrubando um a um os baluartes coloniais e os mercados do imperialismo, enfraquecendo pois o próprio imperialismo. 0 fato da China aparecer como aliada e não como subordinada da URSS enfraquece o poder do Kremlin sobre os PCs. Isto se uniu às transformações internas na URSS: o proletariado derrotado e quebrado da velha geração, que presenciara à onda de derrotas antes da guerra e vira o triunfo da burocracia, deu lugar a novas gerações jovens, invictas, que derrotaram o imperialismo alemão, gerações que foram alentadas pelos contatos com os operários europeus e pela revolução colonial, com um grau cultural muito mais elevado devido aos progressos gigantescos da economia socialista, compostas, fundamentalmente, de operários industriais e não de camponeses como em 1922. Acabou-se o atraso, o cansaço e o desalento das massas russas. Elas confiam na revolução mundial e sentem o peso das arbitrariedades e dos entraves burocráticos. Por isso, a burocracia tem de fazer-lhes concessões. (POR. Frente Operária,n.2, dezembro de 1952, s/p)

Em suas interpretações, os militantes trotskistas resgatam muitos elementos da dicotomia entre agrarismo e industrialismo (FERREIRA, 2005) que marcou as análises do PCB desde seu surgimento. A lógica geral encontrada no documento que trata do cenário russo se repete na leitura que o POR fazia da figura de Getúlio Vargas e das estratégias que formulava para fazer frente ao seu governo. Para o partido, o presidente era o representante do imperialismo aliado ao latifúndio, e só conseguia manter a legitimação da sua liderança com base em setores da sociedade distantes do meio urbano e que, portanto, não haviam experimentado o processo civilizador da industrialização.

Essa oscilação ganhou escalas maiores após o entrismo no PCB, em 1955. A identidade do partido ficou ainda mais fragilizada diante da força das teses pecebistas. Seus militantes, embora tenham redobrado os esforços críticos às políticas comunistas, assumiram, a cada vez mais, o ponto de referência da compreensão comunista da realidade brasileira; repetiam e aplicavam a fórmula do "país semicolonial e semifeudal" de maneiras cada vez mais contraditórias. Em várias de 
suas apreciações, o POR transitava de maneira bastante indecisa entre a adesão e a rejeição aos postulados comunistas. Em um artigo intitulado "O novo programa do PCB" (POR, 1955), dedicado a discutir a Resolução Política aprovada no IV Congressodo Partido Comunista Brasileiro, de 1954, os trotskistas questionam:

É possível "a industrialização intensiva, garantir plena democracia para o povo, assegurar aos operários e demais trabalhadores suas conquistas e seus direitos, proporcionar a toda a população brasileira uma vida próspera, livre e feliz"? É possível às "camadas democráticas e progressistas" regenerar tão maravilhosamente o regime capitalista? Ou isso não passa de uma idealização reacionária dos exploradores "nacionais"? (POR, Frente Operária, n.14., fevereiro de 1955, p.14).

Mas afirmam, em seguida: "Neste país as relações de produção não são semi-feudais (apesar da existência de importantes restos semifeudais)" (idem). O POR segue então novamente na direção já traçada pelo PCB, embora pese a mão, em seu discurso, na rejeição sistemática de cada ponto do programa comunista.

Quanto às relações do imperialismo com a burguesia nacional tão ressaltadas no programa pecebista, os trotskistas faziam uma avaliação que não chegava a contradizer totalmente a idéia da existência uma camada industrial nacionalista, que precisava ser fortalecida numa aliança contra a exploração imposta pelo capital externo. As considerações feitas pelo POR a essa idéia geral aparecem mais como uma variação de nuances que uma oposição resoluta a esse princípio geral. Assim, ainda que afirmassem "rejeitar as quatro candidaturas"15 e que as eleições de outubro de 1955 não passariam de "mais uma farsa burguesa", os trotskistas avaliavam que o processo, em si, afetava os interesses mais conservadores, pois expressava alguma potencialidade para a luta de massas - mesmo que não houvesse possibilidades legais de construir uma candidatura operária. Em suas palavras:

A burguesia nacional não tem condições para uma política abertamente anti-imperialista. Mas, por outro lado, não deseja entregar-se por qualquer preço ao imperialismo; ela quer venderse, mas vender-se mais caro.[...] A ameaça da guerra entre exploradores e explorados, porém, faz com que as burguesias nacionais não possam regatear muito. Por essa razão, a campanha eleitoral da burguesia - comandada, hoje, por Juscelino Kubitschek - não será nem a sombra da demagogia de Getúlio Vargas. Se o getulismo era tímido, o juscelinismo era ainda mais medroso e

\footnotetext{
${ }^{15}$ As candidaturas eram as de Juscelino Kubitschek, pela coligação PSD-PTB; Juarez Távora, pela UDN e outros partidos menores; Ademar de Barros, pelo Partido Social Progressista (PSP) e Plínio Salgado, pelo Partido da Representação Popular (PRP).
} 
covarde. A reação sabe muito bem disso e dai que sua oposição a Juscelino não seja uma oposição a um candidato "nacionalista", mas uma oposição a um processo eleitoral que pode dar expressão ao espírito da luta das massas. 0 que a reação quer não é evitar que Juscelino seja candidato; ela quer é evitar que haja eleições. (POR, Frente Operária, n.15, maio de 1955, p. 6 e 7)

Já durante o governo JK, o "Frente Operária" publica um texto no qual fica mais clara a posição do POR diante das políticas desenvolvimentistas. Assinado por Leôncio Martins Rodrigues, o artigo se inicia levantando algumas das questões gerais que mais preocuparam os teóricos do desenvolvimentismo. Afirma-se que, apesar de atravessar um período de industrialização e progresso, o Brasil continuaria sendo um país semi-colonial sujeito à dominação das grandes potências imperialistas, além defundamentalmente agrícola, exportador de café e algodão.

Aparecem também outras preocupações típicas do programa dos desenvolvimentistas de esquerda. A necessidade da criação de uma infra-estrutura para a implementação de um parque industrial no país, bem como a nacionalização das indústrias estrangeiras mais importantes e a realização da reforma agrária seriam omissões do programa de Juscelino Kubitschek que transformariam sua plataforma de um governo industrializante em algo muito insuficiente diante das necessidades do país.

Para se libertar do asfixiante controle que os grandes trustes internacionais exercem sobre a economia brasileira, o país necessita montar uma indústria pesada, com fabricação em grande escala de caminhões, tratores, locomotivas, motores; precisa de um parque siderúrgico, precisa montar uma rede de usinas hidroelétricas, etc. Para realizar isto, a burguesia nacional "industrialista" necessita de capitais, coisa que não possui em quantidade suficiente e necessária. Para remediar tal situação, o ex-governador mineiro pensa em recorrer (e já o está fazendo) ao "auxílio" de capitais estrangeiros. Mas, os "trustes" e monopólios imperialistas não pretendem aplicar seus capitais no Brasil com a finalidade de incrementar nosso progresso, mas sim para tirar lucro com a exploração desenfreada da mão de obra nacional. [...] Para permitir nosso real desenvolvimento econômico é imprescindível a expropriação sem indenização dos trustes imperialistas que sugam, controlam e entravam o progresso do Brasil. [...]Porém, além de tudo isso, Juscelino Kubitschek omite um ponto fundamental, sem cuja realização não se pode nem pensar em progresso no Brasil: a reforma agrária. [...]. Enquanto subsistirem grandes latifúndios improdutivos (ou de baixíssima produtividade) o regime da "meia" e da "terça" (vestígios feudais) nosso país não sairá da miserável condição de semi-colônia, gozando de independência política apenas formal, apesar dos 
imensos recursos que possui. Sem reforma agrária não há progresso real no Brasil. (grifos do autor. Rodrigues in POR, Frente Operária, n.18, maio de 1956, s/p).

Em relação à postura do $\mathrm{PCB}$ diante do governo de JK e dos "choques inter-burgueses" (referindo-se especificamente à crise de 11 de novembro de 1955), o POR afirma quea direção do Partido Comunista se mantinha "marchando a reboque da burguesia nacional", em uma trajetória totalmente desorientada.

Como alternativas concretas à ação dos comunistas, o POR indicava saídas que deveriam ser buscadas estritamente no plano pragmático. Mas não há maiores questionamentos a respeito do espírito geral das orientações do PCB e suas propostas programáticas mais amplas sobre o desenvolvimentismo, sendo o próprio PCB, segundo os trotskistas, o protagonista dessas ações.

Em 1957, depois de aparecerem os primeiros reflexos mais significativos da crise internacional do comunismo ${ }^{16}$ dentro do partido, o POR passa a se dedicar não só à avaliação dos movimentos da direção do partido, como também das correntes que surgem ao longo da disputa. $\mathrm{Na}$ esperança de finalmente colher os frutos de sua ação dentro do PCB, os trotskistas acompanham passo a passo a fragmentação da coalizão dirigente, buscando, ao mesmo tempo, alvejar as lideranças das principais frações em disputa e ganhar a simpatia das bases que impunham questionamentos à política que vinha sendo realizada até o momento. Dessa forma, sugeria-se que a única saída para a crise de legitimidade aberta nos quadros do PC seria uma revisão completa de suas orientações, um movimento que deveria ir muito além da recomposição dos altos escalões do partido.

Mas a avaliação segue indicando que os prognósticos não são animadores para os trotskistas. Afinal, desde o início da crise pela qual passava o Partidão, das frações que ganharam mais notoriedade na disputa e adesão de maiores parcelas das bases, nenhuma se aproximava das políticas do POR. Em outra passagem do mesmo texto acima citado, o partido chega a uma interessante conclusão:

Um dos motivos que tem permitido ao Presidium stalinista manter-se no controle do PCB é a inexistência de uma oposição mais organizada, [grifo nosso] dispondo de uma plataforma coerente que mobilize as bases e aglutine em torno de si aqueles elementos (que são inúmeros) que anseiam por uma modificação.

16 Trata-se do período de crise aberto pelo XX Congresso do Partido Comunista da União Soviética (PCUS) e a leitura dos relatórios de Kruschev, denunciando os crimes do regime stalinista, em 1956. Sobre os impactos dessa crise no PCB, ver (REIS, 2002). 
A luta de tendência, a oposição ao retorno do stalinismo, se bem já tenha atingido todos os escalões da organização pecebista, continua sendo, fundamentalmente, escaramuças na cúpula, de onde só os quadros médios e dirigentes têm pleno conhecimento. (Rodrigues in POR,Frente Operária, n.18, maio de 1956, s/p)

Ao reconhecer que não havia organizações, dentro do PCB, que cumprissem o papel de tensionar o partido por dentro e levar a crise aos fins que almejavam atingir desde que se voltaram para a ação dentro do campo dos comunistas, os trotskistas abriam flancos para que se chegasse à conclusão, mais cedo ou mais tarde, de que, mesmo com todos os esforços empregados, a tática do entrismo não funcionou.

0 alcance e a consistência dessa crítica diminuem progressivamente. As contradições vividas pelos militantes trotskistas se tornam tão agudas que passam a influenciar mais notadamente nos textos. Avaliando a impossibilidade da composição de alianças duradouras dos comunistas com a burguesia nacional, o POR explica que tal situação se atribui ao fato "de não existir uma burguesia nacional anti-imperialista e democrática nos moldes idealizados pela direção stalinista", mas recua, logo em seguida, dizendoque não nega "a existência de grupos capitalistas nacionais que oferecem uma certa resistência aos planos mais estranguladores dos EEUU” (idem).

Por outro lado, ainda que tenha consumido muito da sua capacidade propositiva, o esforço em realizar uma análise pormenorizada das propostas das diferentes correntes em disputa na crise do PCB possibilitou ao POR uma crítica ao nacional desenvolvimentismo como ideologia. Discutindo nacionalismo presente no programa dos chamados "renovadores" - corrente que foi expulsa do Partidão ainda no ano de 1957 - os trotskistas destacam:

[...] Quais são as "inovações" dos novos ideólogos do nacionalismo? O nacionalismo apresenta-se como um tipo de ideologia característico dos países subdesenvolvidos, "bandeira anti-imperialista [...] para o estatismo econômico e para a participação cada vez mais intensa das camadas populares na vida política" [...] "O nacionalismo, ao mesmo tempo que exerce a função de ideologia do desenvolvimento econômico exerce também a função de ideologia política das massas. Através dele as massas tomam consciência social de sua posição enquanto parte da nação, etc. Subjacente a toda análise dos "renovadores" está a perspectiva de um impetuoso desenvolvimento econômicoindustrial do Brasil (e de outros países coloniais e semi-coloniais) dentro dos quadros do regime capitalista. [...] Para os "renovadores" o nacionalismo seria a ideologia que uniria operários e capitalistas, latifundiários e trabalhadores agrícolas, a 
ideologia de toda nação. (Campos in POR, Frente Operária. Número indefinido, outubro de 1957. Texto de capa).

As limitações de tal ideologia residiriam na ausência de um estudo mais pormenorizado dos diferentes movimentos nacionalistas ao redor do mundo, especialmente aqueles que vinham se desenvolvendo nos países coloniais. Além disso, os "renovadores" teriam excluído de sua reflexão qualquer delimitação do caráter declasse desses movimentos, o que os obrigaria a reconhecer a fragilidade da "universalidade" de suas proposições.

Seguindo com as ponderações sobre tais movimentos, o POR observa que a simples constatação das diferenças entre o nacionalismo dos países subdesenvolvidos, e o das nações opressoras, o chauvinismo, é insuficiente. 0 aumento da força destes movimentos nos países coloniais se deveria a alguns fatores fundamentais: à ação das burguesias nacionais "buscando seu lugar ao sol"; ao "potencial extraordinário" das massas coloniais e semi-coloniais que, ao estrear na arena política, estariam pressionando as direções burguesas a irem além do que pretendiam e, finalmente, à

ausência de um partido marxista revolucionário de massa em condições de canalizar e orientar o desenvolvimento político dos trabalhadores. Nesta conjuntura, a combatividade e o sentimento anti-imperialista das massas têm sido canalizados pelas camadas industrialistas das burguesias indignas que lhe procuram conferir um sentido nacionalista e utilizá-las como moeda de troca em suas tentativas com as metrópoles e com os latifundiários locais. (idem).

Nesse ponto, fica mais clara a tautologia que guia a lógica geral do pensamento do POR. Resumindo sua avaliação, o cenário - no Brasil e no mundo - era o seguinte: Os movimentos de massas não avançam para além das reivindicações nacionalistas por falta de uma direção consequente. Os PC's seriam os partidos que contavam com as melhores condições de fazer avançar tais lutas, mas, encontravam-se deformados ideologicamente por uma direção oportunista, que freava o avançoda história para manter seus privilégios de casta burocrática. Seria preciso recuperar essas organizações para a luta de massas, pois sua essência era marxista e sua base ainda estaria fortemente ancorada na classe operária, único agente capaz de levar o progresso a cabo e conduzir ao socialismo. Mas, no caso do PCB, isso se mostrava impossível - ou, ao menos, muito improvável: mesmo dentro do partido ao qual os trotskistas se filiaram in bloco, não haveria frações e tendências organizadas a ponto de dar conseqüência às dissensões com a direção. A saída seria confiar a direção desses movimentos, bem como da política comunista, à "única classe capaz de superar o atraso dos 
países semi-coloniais, de terminar as tarefas democrático-burguesas que a burguesia iniciou mas não é capaz de levá-las a seu término [que] é a classe operária, apoiada nas massas agrícolas e pequeno-burgueses pobres" (ibidem).

Ainda durante o governo JK, o POR começa a apresentar os primeiros sinais de afastamento em relação ao PCB. No entanto, por um bom tempo, as dificuldades impostas ao partido não chegaram a colocar o entrismo em questão. Pelo contrário, o POR parecia renovar os esforços para manter a política operando mesmo em momentos em que tudo indicava sua falência e ainda que isso significasse fazer sacrifícios de alguns princípios que dizia defender. Quando as tensões internas no PCB se acirraram e a reorientação de sua linha política resultou na cisão de Agildo Barata e do amplo grupo que o seguiu (a "corrente renovadora"), o POR se empenhou para conter os danos e evitar mais rupturas, posicionando-se contra "qualquer tendência pugnando pelo rompimento precipitado e aventureiro com o PCB, mesmo que isto fosse feito sob a cobertura da proclamada renovação do marxismo" (Frente Operária apud PEREIRA NETO, 2005).

Os questionamentos à política pecebista eram mais notáveis nas discussões geradas a partir das definições dos apoios comunistas a candidaturas eleitorais e da composição de suas alianças partidárias. Em 1956, o partido repudiou a Frente Nacionalista, a frente parlamentar que contava com parlamentares da UDN, da esquerda do PTB e organizações da sociedade civil, mas que tinha o PCB como um de seus principais protagonistas.

A partir de meados do governo JK, o POR desenvolveu algumas críticas que o afastaram relativamente do PCB. Para o partido, haviam se esgotado no Brasil todas as chances de um modelo nacionalista de desenvolvimento, dado o apego ao capital externo no fomento da economia. De 1959 em diante, a antiga caracterização da "crise de crescimento" deu lugar, definitivamente, a uma interpretação do esgotamento do papel do nacionalismo na modernização do país, o que impunha a necessidade da construção de uma frente anti-imperialista para desmascarar supostas práticas nacionalistas nos sindicatos pelegos.

Esse afastamento relativo do PCB chegou a levar o POR a ensaiar movimentos para a formação de um novo partido revolucionário. Durante o período de março de 1959 a janeiro de 1960, o partido chegou a tentar sereunir com os integrantes a LSI (Liga Socialista Independente) e da Juventude Socialista, já queas três organizações convergiam na defesa do lançamento de uma candidatura operária à presidência da República nas eleições de 1960. A tentativa se frustrou 
no final de janeiro de 1960, quando em Conferência, o POR decidiu considerar encerrada a fase transitória de luta pela construção de um partido marxista revolucionário de quadros com base na articulação entre os grupos independentes de esquerda. Voltou a ser defendida a tática do entrismo no PCB, considerada válida até 1963, quando J. Posadas recusou sua validade nos casos brasileiro e no uruguaio.

\section{IV- Conclusão}

Após a análise de seus documentos, concluímos que POR apresentou aproximações relativas ao projeto desenvolvimentista, uma vez que a formulação de suas críticas ao modelo se encontrou bastante limitada pela submissão ao BLA e pela política de entrismo no PCB. No que se refere às suas características organizativas, o partido se mostrou como um grupo altamente centralizado pelo BLA, com baixos índices de autonomia organizativa, o que também contribuiu para esvaziar a sua democracia interna, já que o poder de decisão e de formulação política dos militantes se transferia para as mãos dos dirigentes do Bureau. A agremiação reivindicava $\mathrm{o}$ centralismo democrático criticando 0 autoritarismo do PCB como uma distorção do modelo, mas não conseguiu implementá-lo devido à sua baixíssima institucionalização, chegando a um padrão que mais se assemelhava ao "centralismo autocrático" descrito por Duverger (1987). O entrismo no PCB prejudicou ainda mais a sua institucionalização, já que os limites da organização ficaram mais permeáveis à influência externa.

A formulação programática indica um aumento da pressão dos pressupostos pecebistas sobre as formulações do POR, mas não alteram a orientação geral que já se notava nos textos antes do entrismo: as colorações desenvolvimentistas aparecem com tons mais fortes, assim como as críticas diretas à ação política comunista. Isso se explica pela sobrecarga de tarefas assumida pelos trotskistas, que deviam, na dupla militância, dedicar energias à desconstrução do PCB na tentativa de ganhar seus quadros para o POR. A hostilidade do meio e a transformação da denúncia minuciosa e implacável de cada passo das direções comunistas em prioridade minaram a capacidade propositiva e de autoconstrução do partido. Entre os analisados em nossa pesquisa de mestrado ${ }^{17}$, o caso do POR é o que apresenta as definições mais claras das relações de causalidade entre conformação dos traços organizativos e variações programáticas, ainda que ambas as variáveis tenham bastante peso. Assim como o stalinismo pecebista, o trotskismo também reivindicava o centralismo democrático de Lênin como princípio organizativo básico, embora propusesse que os espaços

17 A pesquisa abrange também os contemporâneos PCB e LSI, em perspectiva comparada. 
de discussão democrática fossem mais considerados que no partido ao qual se apresentava como contraponto.

Ideologicamente, a leitura feita por Trotsky também confere ao "progresso das forças produtivas" um papel central da "marcha da história", mas de uma forma menos linear e com mais peso nas "condições subjetivas" do movimento: na Teoria da Revolução Permanente, afirma-se, grosso modo, que dependendo do contexto (como na Rússia) a história "pula etapas"; o movimento rumo ao socialismo é ininterrupto e deve ser capitaneado pelos seus sujeitos mais conseqüentes, o proletariado urbano industrial. No caso específico do POR, essa orientação ideológica geral sequer realizou toda a sua potencialidade crítica, como se verificou, segundo a literatura, nos partidos trotskistas que o antecederam na história do país. A fragilidade institucional do partido foi, a nosso ver, o principal fator explicativo para as definições dos seus objetivos ideológicos. Em suma: o POR era um partido de baixa autonomia organizativa, baixos índices de democracia interna (ainda que maiores que as encontradas no PCB) e com alguma aproximação ideológica do modelo desenvolvimentista, determinada principalmente pela incapacidade organizativa de formular alternativas programáticas que correspondessem à crítica que propunham ao modelo pecebista.

Ao nos concentrarmos na forma de desenvolvimento do seu programa, observamos que o POR aprofundou, no período em que desenvolveu o entrismo, as críticas às estratégias políticas do PCB, dedicando mais espaço e energia em seu jornal - que também mudou de formato e de público alvo - a longas e detalhadas apreciações das alianças feitas pelos comunistas, bem como das declarações e textos da direção do partido. A formulação de suas próprias análises, de seu próprio programa, no entanto, parece ter ficado em segundo plano. A cada negação de uma proposta comunista, há uma proposta dos trotskistas que não deixa de se aproximar, e muito, daquelas que buscavam questionar. Isso é verificável tanto nos conceitos gerais usados para caracterizar a economia brasileira (em um primeiro momento cita Caio Prado Jr ao negar o caráter semi-feudal da estrutura produtiva do país; em um segundo adota o termo "semi-colônia" e acaba, por último, reafirmando a existência de restos feudais na atividade agrícola) quanto nas políticas mais práticas, como a avaliação dos candidatos (JK não deveria ser apoiado, mas as eleições poderiam, através da sua candidatura, dar expressão à luta das massas), e o programa que sugere para a industrialização do país e para o próprio movimento. 
Dessa forma, a tarefa de desconstruir o PCB representou para o POR, também no nível programático, uma perda de capacidade de construir a si mesmo. A agudez da crítica - que chega a apontar (em oposição às afirmações dos líderes comunistas) o perigo iminente de um golpe militar, forjado nas movimentações das forças políticas conservadoras, em 1955 - não acompanha os mesmos êxitos propositivos, ausente dos seus textos.

No julgamento feito pelos próprios militantes do partido, a fragilidade de sua organização o impedia de oferecer uma alternativa consistente, naquele momento, a um movimento de massas que pudesse fazer frente aos desafios colocados pelas lutas que julgava como primordiais. A política do entrismo é apontada ora como uma estratégia para popularizar o trotskismo, ora como contingência imposta pela hegemonia comunista. Ela serviria, temporariamente, de antídoto ao isolamento enfrentado pelos militantes e ofereceria oportunidades ímpares para o crescimento das bases da organização, a popularização de sua linha e a radicalização da linha do PCB, convertido em seu território de caça.

Mas a prática mostrou que tamanho empreendimento exigiria esforços hercúleos de seus membros, que, desgastados, não conseguiam dirigir energias para a própria organização. Mais que a elaboração de um programa próprio ou de uma organização fortemente institucionalizada a sobrevivência do partido a esse período parece ter sido a grande vitória do POR, ainda que contra todas as tendências.

\section{Referências}

CHAGAS, G. Panorama das ideias trotskistas no país. Jornal da Unesp, n. Edição 260, p. 4, out. 2010.

COGGIOLA, O. 0 trotskismo na América Latina. 3a edição ed.São Paulo: Editora Brasiliense, 1984.

DUVERGER, M. Os partidos políticos. $3^{\mathrm{a}}$ edição ed.Rio de Janeiro: Editora Guanabara, 1987.

FERREIRA, P. R. O Brasil dos trotskistas (1930-1960). Cadernos AEL, v. 22/23, 2005.

JUNIOR, C. P. Formação do Brasil Contemporâneo. Coleção Gr ed.São Paulo: Editora Brasiliense; Publifolha, 2000.

KAREPOVS, D.; NETO, J. C. M. Os Trotskistas Brasileiros e suas Organizações Políticas (1930-1960). In: RIDENTI, M.; REIS, D. A. (Eds.). História do 
Marxismo no Brasil,Volume 5: Partidos e Organizações dos anos 1920 aos 1960. 1a. ed. Campinas: Editora Unicamp, 2007. p. 167-196.

NETO, M. L. P. À esquerda da Esquerda. Trotskistas, Comunistas e Populistas no Brasil Contemporâneo (1952-1966). São Paulo: Editora Paz e Terra, 2004.

NETO, M. L. P. Idéias políticas e organização partidária do POR (1952-1964). Cadernos AEL, 2005.

OLIVEIRA, J. A. DE. POLOP: As origens, a coesão ea cisão de uma organização marxista (1961-1967). Araraquara.: UNESP, 2007.

PANEBIANCO, A. Modelos de Partidos: organização e poder nos partidos politicos. São Paulo: Martins Fontes, 2005.

POR. Frente Operária n5.pdf. jun. 1953.

REIS, D. A. Entre reforma e revolução: a trajetória do Partido Comunista no Brasil entre 1943 e 1964. In: RIDENTI, M.; REIS, D. A. (Eds.). . História do Marxismo no Brasil: Volume 5. Campinas: Editora Unicamp, 2002.

\section{Depoimentos4}

Ruy Fausto. 17 e 18 de abril de 2013.

Tullo Vigevani. 19 de abril de 2013.

Todas as entrevistas foram realizadas por meio eletrônico.

\section{Periódicos}

Frente Operária, № 2. São Paulo, dezembro de 1952

Frente Operária, no 4. São Paulo, 23 de abril de 1953.

Frente Operária, no 5. São Paulo, junho de 1953.

Frente Operária, no 6. São Paulo, julho de 1953.

Frente Operária, no 7. São Paulo, agosto de 1953.

Frente Operária, no 8. São Paulo, setembro de 1953.

Frente Operária, no 9. São Paulo, outubro de 1953.

Frente Operária, no 10. São Paulo, novembro de 1953.

Frente Operária, no 14 . São Paulo, fevereiro de 1955.

Frente Operária, no 15. São Paulo, maio de 1955.

Frente Operária, no 16. São Paulo, agosto de 1955.

Frente Operária, no 17 . São Paulo, setembro de 1955.

Frente Operária, no 18. São Paulo, maio de 1956.

Frente Operária, s/n. São Paulo, outubro de 1957.

Frente Operária, no 31. São Paulo, setembro de 1959. 
Frente Operária, no 31. São Paulo, outubro de 1959.

Frente Operária, no 33. São Paulo, dezembro de 1959.

Frente Operária, no 35. São Paulo, janeiro de 1960.

Recebido em 27 de dezembro de 2013 Aprovado em 16 de janeiro de 2015 


\title{
Developmentalism and political party institutionalisation: POR's unusual Trotskyism (1952- 1960)
}

\begin{abstract}
This article aims to discuss the main organisational and programming ideias from the Revolutionary Worker's Party (POR) (from its foundation in 1952 to 1960), evaluating its strategic positioning in face of the national development projects that took place in the 1950's and the relation between this positioning with the institutional arrangements from the party. The developmentalist ideology adopted by the governments during the 1950's - mainly by Jucelino Kubitschek counted with the participation of many left wing marxist groups from that time, which included, besides the trotskyist party POR organisations such as the Brazilian Communist Party (PCB) and the Socialist Independent League (LSI). The variations between these parties programs and their formulations about developmentalism, besides the differences between their organisational principles, were the subject of our master's degree research, from which part of the results about POR presented in this article are from. Therefore we seek to understand the different levels of this programatic accession among the extreme left wing parties (or the existence of critical or alternative formulations) in the attempt to bring into light an aspect that is in our understanding marginally addressed in many investigations on this subject, that is the marxist oriented party programs that debated PCB's premises - which are more often studied. To debate the manner by which its institutional principles were combined and the elaboration of POR's program we base this test on the theoretical prepositions of Panebianco and Duverger. This study was developed based on bibliographic and documental sources specially from POR's newspaper - called "Worker's Front" - in addition to interviews with the party's former supporters. As a result we observed that POR's original characteristics were the basis for the formation of its political program because it forced the trotskyists to deal with the presence of two extreme strong institutions: the Latin American bureau of the IV International and the PCB. That meant a decrease of its organisational autonomy and the consequential diminish of the party's internal democracy - two indicators present in Panebianco proposals for measuring political party's institutionalisation levels.
\end{abstract}

Keywords: Trotskyism in Brazil, Brazilian left wing political parties; political party institutionalisation; Developmentalism and Marxism 